\title{
Development and Application of Lightweight High Strength Organic Materials
}

\author{
Yang Zhang ${ }^{1, \text { a }}$ \\ ${ }^{1}$ Jiangsu Province Xuzhou Technician Institute, Xuzhou, Jiangsu Province, China
}

\begin{abstract}
This paper summarizes the commonly used organic materials with light weight and high strength characteristics, and introduces their types, characteristics, applications and current development status at home and abroad.
\end{abstract}

\section{Introduction}

According to statistics, $60 \%$ of automotive fuel is consumed in the vehicle's own weight ${ }^{[1]}$, reducing the vehicle's own weight can effectively save energy and reduce emissions. Every 10\% reduction in the vehicle's vehicle quality, the fuel consumption will decrease by $3 \%-7 \%{ }^{[2]}$. The realization of lightweight not only is the automotive industry, but all energy-consuming equipment is an important way to save energy and reducing emissions and developing green and environmental protection. With the research and development of highstrength materials, materials that can meet the strength requirements are not limited to metal materials, and plastics gradually step into the stage of the times.

\section{High-strength engineering plastics}

Engineering plastics, especially high-performance engineering plastics, are widely used because of their good mechanical properties, comprehensive mechanical properties, heat resistance, acid resistance, long life, and good reliability. In order to achieve lightweight of equipment, Wang Tuyuan ${ }^{[3]}$ and others put forward the concept of "plastic substitute steel". Polymers have excellent properties such as light weight, corrosion resistance, high strength, and easy processing. At present, high-strength engineering plastics are used in pipelines, automobiles, construction and other fields. Polyethylene chloride, rubber, polyoxymethylene, polyamide, polyurethane, polytetrafluoroethylene, nylon, and synthetic fibers are used for long time ${ }^{[4]}$. In order to ensure a certain degree of strength of the material, Zhang $\mathrm{Chao}^{[5]}$ and others have proposed steel-plastic composites. The wire-wound mesh skeleton-reinforced plastic composite pipe is reinforced with a high-strength steel wire with a left-right inclination and is formed with a net- like skeleton reinforced with a thermoplastic plastic matrix. The high-performance adhesive resin is used to tightly connect the steel mesh skeleton with the inner and outer plastics using in the coal mine pipeline. This kind of pipe has the advantages of easy installation, easy maintenance, good corrosion resistance, long service life, no scaling, and good water conservancy performance. The wall climbing robot produced by Li Heng ${ }^{[6]}$ chose POM as the body shell in light of the principle of miniaturization. Polyoxymethylene, as an engineering plastic with excellent performance, is known abroad as "steel-reducing" and "ultra-steel". It has similar hardness, strength and steel properties, and it has good performance in a wide range of temperature and humidity. Selflubrication, good fatigue resistance, and flexibility, and it also has good chemical resistance and low cost. In addition, PET (polyethylene terephthalate) has excellent properties such as high strength, high rigidity, good heat resistance, excellent dimensional stability, outstanding chemical resistance, etc. Machinery, automotive parts and other fields have been widely used ${ }^{[7-9]}$.

In the automotive field, the blending of polyethylene (PE) with PP (polypropylene) has high impact resistance. Peugeot bumpers are made from PP/HDPE blends ${ }^{[10,11]}$. Polyamide (PA) has good mechanical properties and thermal stability, so it is an ideal material for producing high-strength, heat-resistant parts. Plastic accelerators are used on German Volkswagen's "Golf" and "Jetta" cars. The pedal, using DuPont's 180 G 33 PA, has low cost, high strength, and good reliability ${ }^{[12]}$.

\section{Lightweight high-strength fiber composites}

Polymer materials have certain advantages, but their strengths are much different from those of metals. Steelplastic composite materials do not fundamentally realize

a113503287@qq.com 
the lightweight and high-strength characteristics of materials. The resin-based composite material is a kind of fiber-reinforced plastic. The low quality of plastic materials and its high-strength performance are currently the major trends.

\subsection{Carbon Fiber Composites}

Carbon fiber (CF) is a kind of high-performance fiber. It has excellent properties such as high specific strength, high specific modulus, fatigue and creep resistance, expansion coefficient, and small friction coefficient, becoming the most important enhancement in composite materials, being one of the most important materials ${ }^{[13]}$. High-strength carbon fibers such as T800, T1000, and T1100 carbon fibers have tensile strengths of $5.49 \mathrm{GPa}$, $6.37 \mathrm{GPa}$, and $6.6 \mathrm{GPa}$, respectively ${ }^{[14]}$.

In the 40th and 50th centuries of the 20th century, carbon fiber composite materials (CFRP) were first manufactured in the United States. In 1950, CFRP was first produced by pulling rayon at a temperature of $2000^{\circ} \mathrm{C}$. It has high specific strength, specific modulus, low density, good anti-fatigue properties, good antivibration performance, strong designability, and high temperature performance. With good moldability and other advantages, high-performance CFRP strength can reach more than ten times of steel ${ }^{[15,16]}$, and is widely used in aerospace and military fields. The specific strength of high modulus carbon fiber/epoxy resin composites is 5 times that of steel and 4 times that of aluminum alloys. Its specific modulus is 4 times that of aluminum and copper. The production of bearing members can exert unique and excellent mechanical properties. ${ }^{[17]}$.

Bie Mingzhi ${ }^{[18]}$ prepare carbon fiber/PA6 composites with high strength, high electrical conductivity and flame retardant properties, which can meet the safety and performance requirements of polymer products in coal mines.

Song Yanjiang [19] added carbon fiber to the thermoplastic polyimide resin for composite reinforcement. The effect of carbon fiber addition and molding method on the mechanical properties of the composite material was experimentally studied. The addition of carbon fiber can significantly improve the room temperature and high temperature mechanical properties of the material, and carbon fiber different types, the degree of improvement is also different; the tensile strength and bending strength of the composite material increase with the increase of the amount of carbon fiber; $J$. Karger-Kocsis [20], who used carbon fiber reinforced thermoplastic polymethyl methacrylate Ethyl acrylate composites and carbon fiber-reinforced thermoplastic polyetheretherketone composites, and their mechanical properties were studied. The results show that the mechanical properties of the composites are determined by the bonding of the resin matrix and the carbon fibers, the toughness of the resin, and the arrangement of the carbon fibers in the resin.

\subsection{Fiberglass}

FRP is a high-strength engineering plastics, its full name is - glass fiber reinforced plastic, which has the characteristics of corrosion resistance, good insulation, high specific strength, low cost, simple process, short production cycle, etc. ${ }^{[21]}$, FRP the traditional products of composite materials are made by the glass fiber winding forming process, such as internal pressure vessels, pipes and tanks, which mainly utilize the properties of fibers with high tensile strength. The advantage of the filament winding method is that the fibers can be arranged according to the stress conditions, thereby improving the mechanical structural efficiency of the product ${ }^{[22-24]}$.

FRP is often used in industrial pipes. The quality of FRP pipes is light. The same size is only $1 / 4$ of the quality of steel pipes and $2 / 25$ of concrete pipes. The pipes contain rich resin layers and the surface is extremely smooth, small resistance, no scaling. When the flow is the same, the pressure loss caused by the FRP pipe conveying medium is about $3 / 5$ of the same inner diameter carbon steel pipe, the conveying capacity can be increased by more than $20 \%$, and the power and energy of the pump can be saved by $30 \%$ to $40 \%$. The resin-based composite material itself has good corrosion resistance. Unlike metal pipes, which require regular anti-corrosion and other maintenance, the service life is much higher than that of steel pipes. Especially in coal mine drainage systems with acidic water quality, corrosion resistance can be achieved, long-term safe and reliable operation, and comprehensive benefits are good. The use situation abroad and the research results of Henan Polytechnic University show that the high-strength double-resistant coal mine FRP pipe does not require maintenance within 30 years, even if it needs repairs, it is very convenient. If the pipe is damaged, it only needs to prepare the raw material with the prepared double-resistant glass steel. System can be repaired ${ }^{[25]}$. Zeng Xiantao ${ }^{[26]}$ and other research and development of a new type of glass fiber reinforced plastic composite material tank, the tank path consists of two parts of rectangular steel core and glass fiber coating, this modified pipe has anti-static, flame retardant, wear resistance The performance partially replaces the steel, the quality is reduced, the surface corrosion resistance is far superior to steel, and the service life can reach 30 years.

\subsection{Kevlar}

"Kevlar" is an aramid composite material with dark yellow fibers, with a diameter of $0.01-0.02 \mathrm{~mm}$ and a density of $1.43-1.44 \mathrm{~g} / \mathrm{cm} 3$. Its greatest feature is its high mechanical properties and good stability. Its strength is $3.6 \mathrm{Gp}$, its modulus reaches $131 \mathrm{GPa}$, and its elongation at break is only $2.8 \%$ and it is insensitive to temperature ${ }^{[27}$, ${ }^{28]}$. It was made by DuPont in the 1960s. This new type of material has low density, high strength, good toughness, high temperature resistance, easy processing and molding and is widely used in military and other fields of defense. Compared with FRP, Kevlar bears the same pressure. The material weight of Kevlar can be reduced by half, and the toughness of Kevlar-laminated sheet is 3 times that of steel, which can withstand repeated impacts, including para-aramid. The specific strength is 6 times that of steel 
Table 1 The main performance of Para aramid with the same brand number ${ }^{[29]}$

\begin{tabular}{|c|c|c|c|c|c|c|c|}
\hline Product brand & $\begin{array}{l}\text { Density/ } \\
\left(\mathrm{g} / \mathrm{cm}^{3}\right)\end{array}$ & $\begin{array}{l}\text { Tensile } \\
\text { strengt/ } \\
\text { (cN/dtex) }\end{array}$ & $\begin{array}{l}\text { Tensile } \\
\text { modulus/ } \\
\text { (cNdtex) }\end{array}$ & Elongation/\% & $\mathrm{LOI} / \%$ & $\begin{array}{l}\text { Decomposition } \\
\text { temperature } /{ }^{\circ} \mathrm{C}\end{array}$ & $\begin{array}{c}\text { Moisture } \\
\text { absorption } \\
\text { rate/\% }\end{array}$ \\
\hline Kevlar29 & 1.44 & 20.3 & 490 & 3.6 & 29 & 500 & 7.0 \\
\hline Kevlar49 & 1.45 & 20.8 & 780 & 2.4 & 29 & 500 & 3.5 \\
\hline Kevlar119 & 1.44 & 21.2 & 380 & 4.4 & 29 & 500 & 7.0 \\
\hline Kevlar129 & 1.44 & 23.4 & 670 & 3.3 & 29 & 500 & 7.0 \\
\hline Kevlar149 & 1.47 & 16.8 & 1150 & 1.3 & 29 & 500 & 1.2 \\
\hline Twaron Reg & 1.44 & 21 & 500 & 4.4 & 29 & 500 & 6.5 \\
\hline Twaron HM & 1.45 & 21 & 750 & 2.5 & 29 & 500 & 3.5 \\
\hline Technora & 1.39 & 24.7 & 520 & 4.6 & 25 & 500 & 2.0 \\
\hline Armos & 1.43 & $35.0-39.0$ & 1050 & $3.5-4.0$ & $39-42$ & 575 & $2.0-3.5$ \\
\hline Rusar C & 1.46 & 36.3 & 1074 & 2.6 & 35 & 575 & 2.25 \\
\hline Rusar HT & 1.47 & 34.7 & 1200 & 2.6 & 45 & 575 & 1.35 \\
\hline
\end{tabular}

wire, 3 times that of glass fiber, and 2 times that of highstrength nylon industrial yarn. After 100 hours at $200^{\circ} \mathrm{C}$, it can still maintain $75 \%$ of its original strength. After 500 hours at $160^{\circ} \mathrm{C}$, it can still To maintain the original strength of $95 \%{ }^{[29]}$, the main types and performance of the world para-aramid are shown in Table 1.

\section{Summary}

Lightweight is the eternal theme of material development, and it is an important way to realize green environmental protection. The quality of organic materials can be reduced to a certain extent compared to that of metal materials. What we need to do now is to increase the strength of organic materials. The effective method to increase material strength is using fiber to strengthen materials.

\section{References}

1. Tang Di, Mi Zhengli, Chen Yulai . Technical Requirements and Research and Development Status of New Type Automotive Steels in Foreign Countries [J]. Steel, 2005, 40(6):1.

2. Gao Jianhong, Wang Min, Wu Qingqing. Study on Resistance Spot Welding of TRIP590 High Strength Steel [M]. 2008 Light metal and high-strength materials welding International Forum Proceedings. Beijing. 2008: 133-9.

3. Wang Tongyuan, Wang Qiqiang. Application and Development of Polymer in Coal Mine Production $[\mathrm{J}]$ Technology and Innovation Management, 2011,1:1 (32)

4. Fang qian. Analysis of the Safety of Polymer Materials Used in Coal Mines [J]. Journal of North China Institute of Science and Technology. 2005, 3: $1(2)$

5. Zhang Chao, Sun Yunguo, Han Qunliang, Peng Xinyun. Application of Steel Wire Mesh Framework Polyethylene Composite Pipe in Coal Mine [J]. Coal Technology. 2009, 3: 3(28)

6. Li Heng. Research on the Dynamic Characteristics of a Wall-climbing Robot and Its Simulation Analysis [D]. Qingdao University of Science and Technology . 2010, 4

7. Ulrich Thiele . Structural change in the polyester industry[J]. Man-made fiber yearbook ,2000:4

8. Papke N.,Karger-Kosis J . .Thermoplastic elastomers based on compatibilizedpoly (ethylene terephthalate) blends:effect of rubber type and dynamiccuring $[\mathrm{J}]$. Polymer,2001,42:1109

9. Papke N.,Karger-Kosis J . .Thermoplastic elastomers based on compatibilizedpoly(ethylene terephthalate) blends:effect of rubber type and dynamiccuring[J] . Polymer,2001,42:1109

10. Plast, $1987,18(7): 113-115$ 
11. Gubitz Franz Kunststoffe, 1987,32(10):33-37

12. Kunststoffe, 1987,21(9):30-32

13. Rong Huaiping. Study on the Fabrication of Nanomaterials on Carbon Fiber Surfaces and Properties of Their Composites [D] Donghua University. 2013, 9

14. S.Chand. Carbon fibers for compos ites[ J] . Journa 1 of Material science, 2000, $35: 1303 \sim 1313$.

15. Li Wei, et al. Chinese Optics and Applied Optics Abstracts[J]. 2011, 4(3):201-212.

16. Zhang Hanying, Liu Ming. Development and Application of Carbon Fiber Composites [J]. Engineering plastics applications. 2015, 11:11(43)

17. Zhou Xiya . Composite materials $[\mathrm{M}]$. Beijing: Chemical Industry Press, 2005

18. Bie Mingzhi, Li Youbing, Liang Quancai, Du Jing, Chen Jian. Development of Mine Carbon Fiber Composite Nylon 6 Impeller Material [J]. Plastic industry. 2013, 12: 12 (41)

19. Song Yanjing, Wang Xiaodong, Wang Wei et al. Carbon fiber reinforced thermoplastic polyimide and composites thereof [J]. Journal of Materials Science and Engineering, 2007, 25(3): 363-366.

20. Karger-Kocsis J, Yuan Q, Mayer J, et al. Transverse impact behavior of knitted carbon-fiber fabricreinforced thermoplastic composite sheets[J]. Journal of Thermoplastic Composite Materials, 1997, 10(2): $163-172$.

21. John P.Busel .FRP Composites For Civil Infrastructure Applications. Plastics in Building Construction . VolumeXXII Number, 1998, 11

22. Zheng Nongfeng, Howard G .Allen, Stuart S .J .Moy .Study of Stress Concentrations in Woven Composites.Journal of Reinforced Plastics and Composites, 1999, $3: 18$

23. B .Gommers, I .Verpoest, P.Houtte .Analysis of Knitted Fabric Reinforced Composites: PartII . Stiffness and Strength.Composites PartA 29A, 1998

24. M .Bannister, I .Herszbery .The Manufacture of Glass/ epoxy Composites With Multi-layer Woven Architectures.Volume29A, 1998.

25. Geng Yungui, Wang Yuqing, Li jiangzhong. Application of Resin Matrix Composites in Coal Mines [J]. Material Guide. 2014, 5 :(28)

26. Zeng Xiantao, Guo Jingpu. Coal Mine Shaft FRP Composite Material Tank Road [J]. China Engineering Science . 2002 , 12: 12(4)

27. Ian O'Connor, Hugh Hayden, Stephen O'Connor, Kevlar coated carbon nanotubes for reinforcement of polyvinylchloride[J], 2008, 18, 5585-5588.

28. Zhang Chengxiu, Guan Baoqiong. Application of Kevlar Fiber Composite Materials in Strengthening of Civil Engineering Structures [J]. Synthetic fiber, SFC, 2007(4).

29. Li Ye. Development Status, Technical Analysis and Prospect of Para-aramid [J]. Synthetic fiber, SFC, 2009(9) 